\title{
Vessel Wake Prediction Tool
}

by Michael A. Hartman and Richard Styles

PURPOSE: The purpose of this Coastal and Hydraulics Engineering Technical Note (CHETN) is to introduce a desktop application that can be used as a screening tool to assess the relative contribution of vessel wake energy to erosion as compared to that from currents and tides. The application uses simplified algorithms reported in the literature that predict wake height as a function of vessel speed and other parameters. The tool also estimates the maximum shear stress and energy dissipation, which are used as a proxy for erosion potential. This CHETN presents a brief description of the vessel wake algorithms and then describes the desktop application software to help familiarize the user with the layout and other features. The CHETN concludes with conditional limitations that should be considered before using the application.

INTRODUCTION: One of the U. S. Army Corps of Engineers (USACE) primary missions is to maintain safe and efficient vessel passage in our nation's navigable waterways. Vessel-generated wake can mobilize bed sediment, leading to shoreline erosion and reduced water quality in shallow areas (Maynord 2008). High-fidelity numerical models can predict the generation and propagation of vessel wake but require considerable computational resources and time to implement. Loworder estimates of vessel wake may be appropriate for some situations, such as screening applications or cases when the resources for a quantitative prediction are not available or warranted. In situations where detailed wake analysis is not required, a number of simplified vessel wake algorithms have been developed in the past (Sorensen 1997). An advantage of these algorithms is that they are formulated using vessel characteristics such as speed, beam, length, and draft and therefore can be programmed and incorporated into a desktop analysis tool with a simple user interface. This CHETN serves as a user guide for a Vessel Wake Prediction Tool (VWPT), which can support navigation studies requiring knowledge of potential effects of vessel wake.

The concept presented here is derived from previous USACE projects in which simplified models were used to assess the effects of vessel wake on shoreline erosion (Maynord 2008). The VWPT computes the relative contribution of energy dissipation due to vessel wake compared to the ambient dissipation caused by tidal and river flow. It also computes estimates of the bottom shear stress. A stochastic feature is included to assess the cumulative effect of multiple vessels operating in a given waterway. The VWPT also predicts the decay in wave height away from the vessel using low-order empirical equations reported in the literature. Some of the equations were validated with limited data, but the overall consensus drawn from the literature is that more validation is needed. As such, the strategy is to use the existing formulas to build the interface and then incorporate newer information as it becomes available to improve model performance and applicability while maintaining an easily accessible and robust computational tool. The approach ensures that a user can quickly compute the results and run multiple vessel scenarios to explore sensitivity to the model parameter space and multiple project alternatives.

BACKGROUND: Simplified vessel wake models were developed in the past to investigate the relative contribution of vessel wake to other sources of energy such as river flow and tides (Maynord, 2008; Styles and Hartman 2018). Sorensen (1997) and Maynord (2005) provide a 
review of simple vessel wake models that have been used to compute maximum vessel wake and in some cases, the decay in wave height as the waves propagate away from the ship. The vessel wake models supported by the VWPT are listed in Table 1. The first column is the model name, and the second column is a short description of the conditions under which the model was developed. Because the wake energy is dispersive, the highest waves occur near the vessel and become smaller as the wave train propagates away from the vessel. Each model uses some form of an empirical decay function to represent the reduction in wake height with distance away from the vessel. The mathematical formulas can be found in the references presented in Table 1.

\begin{tabular}{|c|c|}
\hline Model Name (year) & Description \\
\hline $\begin{array}{l}\text { Balanin and Bykov } \\
\text { (1965) }\end{array}$ & $\begin{array}{l}\text { Vessel wake height at the channel bank. Model results were validated using } \\
\text { wake data along navigation canals of fairly restricted width. }\end{array}$ \\
\hline Bhowmik (1975) & $\begin{array}{l}\text { Regression performed using one vessel with unknown hull type traveling at } \\
\text { three different speeds. This model formulation does not include water depth, } \\
\text { so it is expected that the equation would only be for deep water waves. }\end{array}$ \\
\hline USACE (1980) & $\begin{array}{l}\text { Bow diverging wave heights at the river bank along navigation channels. This } \\
\text { model has been applied for commercial tows on the Ohio River. It was most } \\
\text { likely developed for restricted channel sizes since distance from vessel is not } \\
\text { employed. The model is valid for tugs and motor vessels. }\end{array}$ \\
\hline $\begin{array}{l}\text { Bhowmik, Demissie, } \\
\text { and Guo (1982) }\end{array}$ & $\begin{array}{l}\text { Vessel wave data from } 59 \text { barge tows with configurations ranging from } 2 \text { to } \\
18 \text { barges plus a tug traveling on the Illinois and Mississippi Rivers. } \\
\text { Multivariate regression analysis resulted in a correlation coefficient of } 0.78 \text {. } \\
\text { While wave heights were collected at several distances away from the sailing } \\
\text { line, there is no regard for distance from the ship in the final formulation. }\end{array}$ \\
\hline Blaauw et al. (1984) & $\begin{array}{l}\text { Based on Delft field and laboratory measurements. The model accounts for } \\
\text { the distance from the vessel's side to the point where the wave height is } \\
\text { being calculated. There is a coefficient corresponding to vessel hull type. } \\
\text { NOTE: This coefficient ranges from } 0.25 \text { (for an inland motor vessel) to } 0.8 \\
\text { (for a loaded pushing unit); however, the authors' formulation is hard-coded } \\
\text { for } 0.25 \text {. }\end{array}$ \\
\hline PIANC (1987) & $\begin{array}{l}\text { Model was validated using waves generated by tugs, patrol boats, and } \\
\text { loaded conventional inland motor boats in inland waterways. }\end{array}$ \\
\hline $\begin{array}{l}\text { Sorensen and Weggel } \\
\text { (1984) }\end{array}$ & $\begin{array}{l}\text { Only valid for Froude numbers ranging from } 0.2 \text { to } 0.8 \text {. This model } \\
\text { incorporates vessel geometry in the formulation of wave height. }\end{array}$ \\
\hline Bhowmik et al. (1991) & $\begin{array}{l}\text { Data were measured from waves generated by } 12 \text { different recreational } \\
\text { vessels ranging in length from } 3.7 \text { to } 14.3 \text { m and draft from } 0.1 \text { to } 0.76 \mathrm{~m} \text {. } \\
\text { Vessels were traveling at different speeds that ranged from } 3.2 \text { to } 20.3 \mathrm{~m} / \mathrm{s} \text {. } \\
\text { The length and draft of the vessels are accounted for, but the hull forms are } \\
\text { not. The lack of water depth in the formulation indicates that applications } \\
\text { should be limited to where the vessel Froude number }\left(F r_{l}=U / \sqrt{g L}\right) \text { is less } \\
\text { than } 0.7 \text {, where } U \text { is the vessel speed, } g \text { is gravity, and } L \text { is the vessel length. }\end{array}$ \\
\hline Maynord (2005) & $\begin{array}{l}\text { Both historical and newly-collected wave data from Johnson Lake near } \\
\text { Soldotna, Alaska, were used to develop an empirical wake height model for } \\
\text { recreational craft. The wake model was for flat bottomed, V-hull, and tri-hull } \\
\text { recreational craft. Comparison to independent data demonstrated appropriate } \\
\text { trends in wake height predicted by the model. }\end{array}$ \\
\hline
\end{tabular}


Bottom Stress and Energy Dissipation Calculation Due to Vessel Wake. The methodology and equations used to derive the bottom stress and energy dissipation calculations are presented in Styles and Hartman (2018). The calculations use established vessel dynamic and linear wave theories to convert the group velocity, derived from vessel speed, to wave period and then to wavelength through the linear dispersion relationship. The wave height, local water depth, and wavelength are used to compute the bottom orbital velocity, which in turn is used to compute the shear stress through a quadratic drag law. The drag coefficient is defined in terms of the grain roughness for a noncohesive sediment bed. Because the model predicts maximum wave height, the bottom stress represents the maximum stress over a wave cycle. Real vessel wake includes a train of waves within an envelope of varying heights that diminish with distance away from the vessel. The model prediction represents only the contribution of vessel-induced bottom stress, since it does not include all potential sources of energy dissipation (e.g., white-capping, wave breaking). The wave energy equation is a function of the wave height and computes the energy per unit planform area. Multiplying the expression by wavelength gives the energy dissipated per unit crest length. By assuming the wave propagates normal to the shoreline, the model predicts wave energy dissipated per unit length of shoreline. A detailed derivation of the energy and stress equations is provided in Styles and Hartman (2018), and the dispersion relationship and orbital velocity equations can be found in Dean and Dalrymple (1991) or any standard text on ocean wave theory.

River and Tidal Energy Dissipation. River energy dissipation is a measure of the bank erosion potential caused by natural river currents. Assuming the change in potential energy of the water column over a unit reach of river balances the frictional drag to maintain constant discharge, the energy dissipated per unit length of river, $E_{R}$, is written as

$$
E_{R}=\operatorname{s\rho g} Q
$$

where $s$ is river slope, $\rho$ is fluid density, $g$ is gravity, and $Q$ is river discharge. Maynord (2008) noted that the energy responsible for erosion occurs in the shallow areas near the bank and therefore represents only a fraction of the total energy integrated across the river width. He noted that this is between 1\% and 5\% of the total energy dissipated at the bed. Maynord (2008) argued that the energy dissipated in the deeper parts of the channel does not contribute to bank erosion, so Equation (1) should be multiplied by $0.01-0.05$ to obtain a more realistic expression for energy dissipation at the shoreline. Based on average values reported by Maynord (2008), a value of 0.02 is used in the VWPT.

In coastal areas, the dominant source of frictional dissipation is often associated with tidal currents. Assuming a sinusoidal tidal current, the energy dissipation per unit planform area averaged over a tidal cycle is written as

$$
E_{T}=(4 / 3 \pi) b_{c} \rho c_{d} U_{0}^{3}
$$

where $b_{c}$ is channel width, $c_{d}$ is the drag coefficient, $U_{0}$ is the maximum tidal velocity over a tidal period, and $\rho$ is water density (Styles and Hartman 2018). Similar to rivers, only a fraction of tidal energy is dissipated at the shoreline so that Equation (2) is multiplied by the same fraction (0.02) to represent the energy dissipated by the tide per unit length of channel. The vessel wake, river and 
tidal energy dissipation equations are expressed in units of energy per unit length of channel (Styles and Hartman 2018).

VESSEL WAKE PREDICTION TOOL DESCRIPTION: The VWPT is written in MATLAB, a commercially available software package designed for high-performance data analysis, model building, and visualization. Because not all users have access to MATLAB, an executable file has been developed for Windows platforms. The VWPT desktop application can be downloaded onto a Windows-based system and used independently of the underlying MATLAB software. The user must also download the vessel wake installer (vwpt installer.exe) from the Coastal Inlets Research Program (CIRP) website: https://cirp.usace.army.mil. Once the installer is launched, the user will be prompted to specify the install location. The executable will check to see if the MATLAB Runtime Environment (MRE) is currently installed. If it is not, the installer executable will automatically download the MRE from the MathWorks servers. Once the MRE is downloaded and installed, the VWPT can be launched. The VWPT uses metric units, and each input box denotes the proper dimensions. After the VWPT is launched, the following command window is displayed (Figure 1).

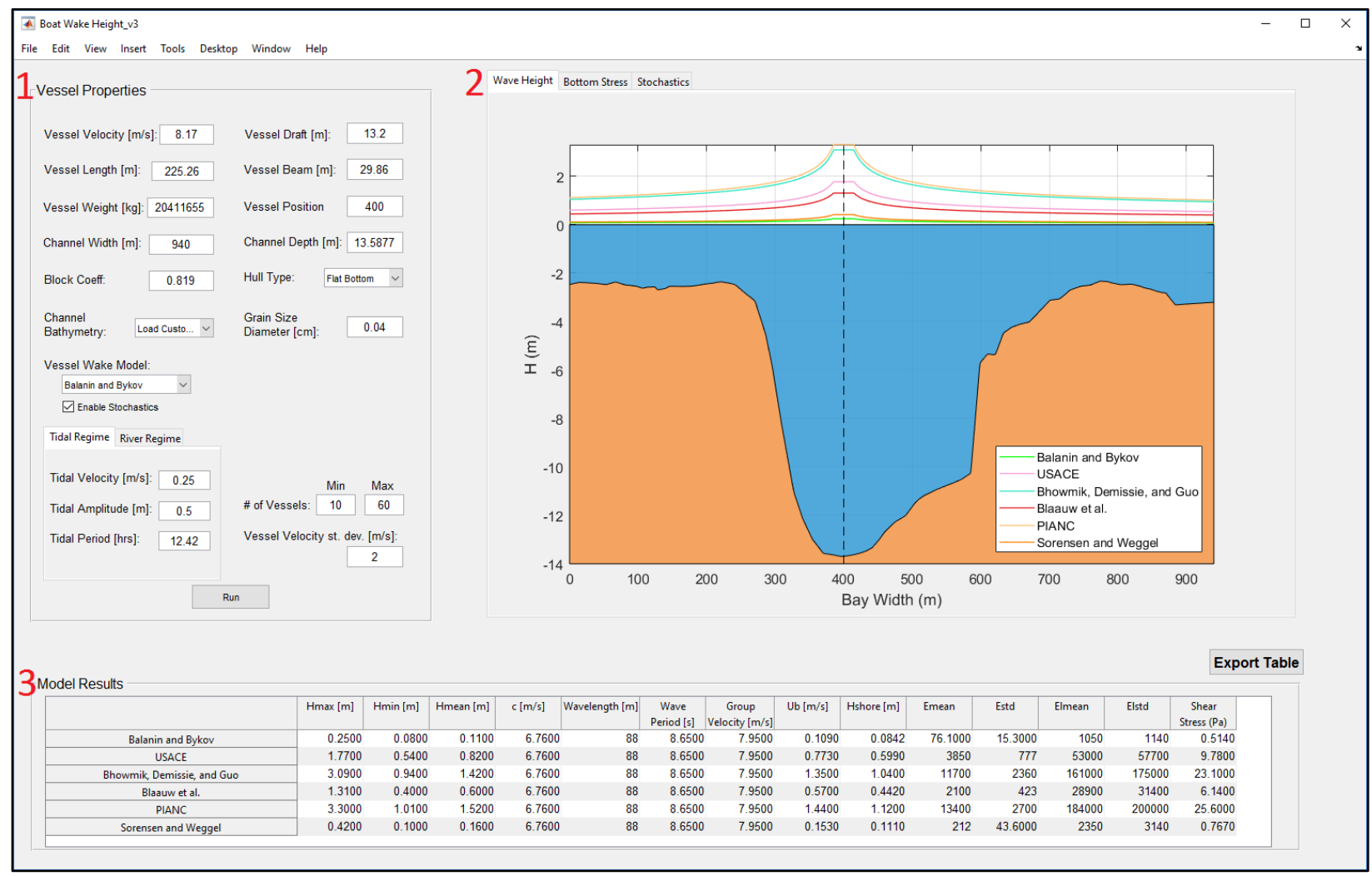

Figure 1. VWPT primary user interface showing the major components of the tool (1 - Vessel Properties, 2 - Graphical Model Output, and 3 - Model Results).

The window is subdivided into three regions: (1) Vessel Properties - where the user provides the input for the vessel characteristics and environmental variables for stochastics, (2) Graphical model output (Wave Height tab) - where the channel cross-section and the wake-height profile for the selected vessels are viewed, and (3) Model Results - where the output wave characteristics and an optional tab to generate an excel spreadsheet containing the input and output information are displayed. Each subsection is further described herein. 
Vessel Properties. The user may enter the vessel parameters, which include speed, beam, draft, length, hull type, and mass. The user also enters the maximum water depth, the cross-shore position of the vessel, and the median sediment grain size of the bed. Depending upon the vessel mass, the model will automatically select the appropriate algorithms from the list of models.

Bathymetry Profile and Cross-Sectional Coordinate System. The model has three choices for the generation of bathymetry cross-sections: (1) constant depth, (2) equilibrium profile, or (3) user-defined profile. The profile type is chosen from the Channel Bathymetry tab. The constantdepth profile (1) creates a flat-bottom channel with a constant depth and width specified from values in the Water Depth and Channel Width boxes, respectively. The equilibrium profile (2) produces an exponential decrease in water depth based on the equilibrium profile, $h(x)=A x^{2 / 3}$, where $A$ is a constant, $h$ is depth, and $x$ is the cross-shore position starting at the sailing line and ending at adjacent shorelines (Dean 1991). The parameter $A$ is a function of bed grain size, and the model automatically computes the value of $A$ associated with the input grain size. The profile is symmetric about the mid-point of the domain regardless of the position of the vessel, and the total domain width is equal to the value entered in the Channel Width box. The user-defined profile (3) reads an ASCII text file that contains the bathymetry data. The file must be in column format with the first column representing the horizontal position across the channel and the second column as depth (reported as positive values). Note that the cross-section represents the distance from bank to bank and not the width of the navigation channel. To represent an engineered channel set within a wider bay, the user should input a bed profile that includes the channel cross-section as well as the embayment or shallow region outside the channel.

Wave Height Tab. This window displays a graphical representation of the bed profile and the wake height as a function of the distance from the vessel (see Figure 1). The minimum permissible water depth is $1 \mathrm{~m}$ to ensure that the wave stress calculations remain stable. The figure displays the results of all wake models based on the inputs defined by the user. All the wake algorithms include a decay term so that all of the profiles decrease with distance from the vessel. The vessel centerline is denoted by the vertical dashed line. The wave height on either side of the vessel centerline is uniform and indicates the width of the vessel. The maximum height determined from the respective vessel wake model is applied at the half-width of the vessel and decays from that point outward.

Bottom Stress Tab. This window is similar to the wave height display but shows the bottom shear stress as a function of distance from the vessel (Figure 2). In general, the stress decreases with decreasing wave height but increases with decreasing water depth. For the case of a constant depth, the stress will decay away from the vessel, but for an equilibrium or user-defined cross-section, the stress may increase closer to shore as the water depth decreases and the bottom orbital velocity increases. The figure also shows the critical shear stress for the initiation of sediment motion based on the grain size input (Shields 1936). The bed profile is highlighted in green where the computed stress is less than the critical and highlighted in red where the computed stress is greater than the critical. This feature helps to identify regions where wakeinduced erosion is more likely to occur. By altering the model inputs, such as vessel speed or the wake height model, the VWPT allows the user to identify the magnitude of changes to the shear stress profile and the associated regions that indicate erosion. 


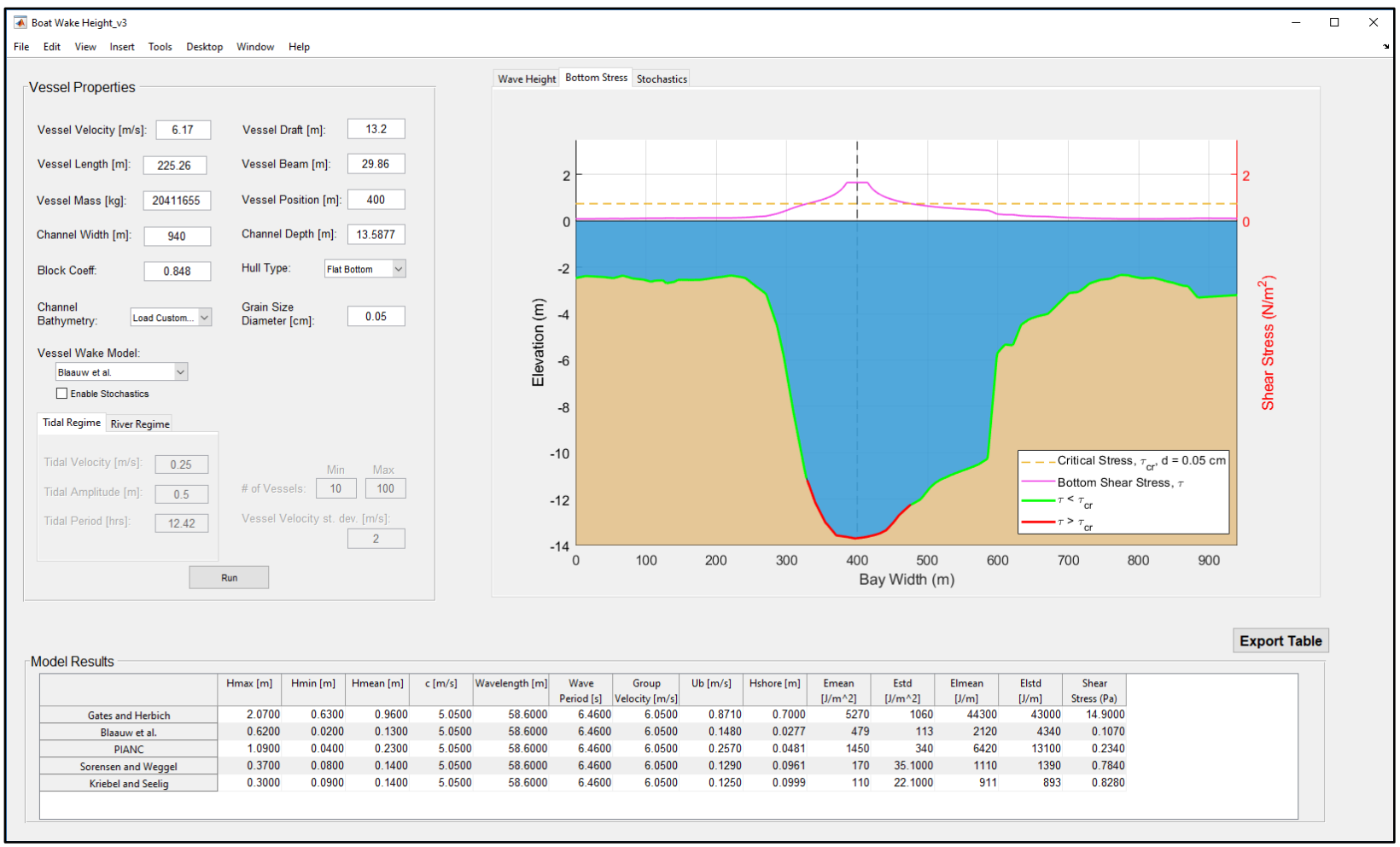

Figure 2. VWPT Bottom Stress tab showing the bottom stress along the cross-sectional profile and model output.

Stochastics Tab. The Stochastics tab allows the user to establish what-if scenarios to determine the cumulative energy dissipation caused by increasing the number of vessel passages in a given timeframe. As an example, this feature could be used to identify the maximum sailing speed or vessel density permitted near a protected area that ensures both efficient navigation and habitat sustainability due to the potential effects of vessel wake. Figure 3 shows the energy dissipated per unit length of shoreline as a function of the total number of vessel passages in a given time period. The equivalent energy due to either the tide or river flow is denoted as a horizontal dashed line. If the vessel wake energy is the same order of magnitude or greater than the river or tidal energy, then the vessel is contributing an equal or greater amount of energy to the system. If the river or tidal flow is representative of the present erosion potential, then the effects of vessels will be additive and could increase the potential for bank erosion. The tool does not calculate a direct erosion rate but rather predicts the wave energy dissipation, which is used as a proxy for erosion potential in comparison to river or tidal energy. 


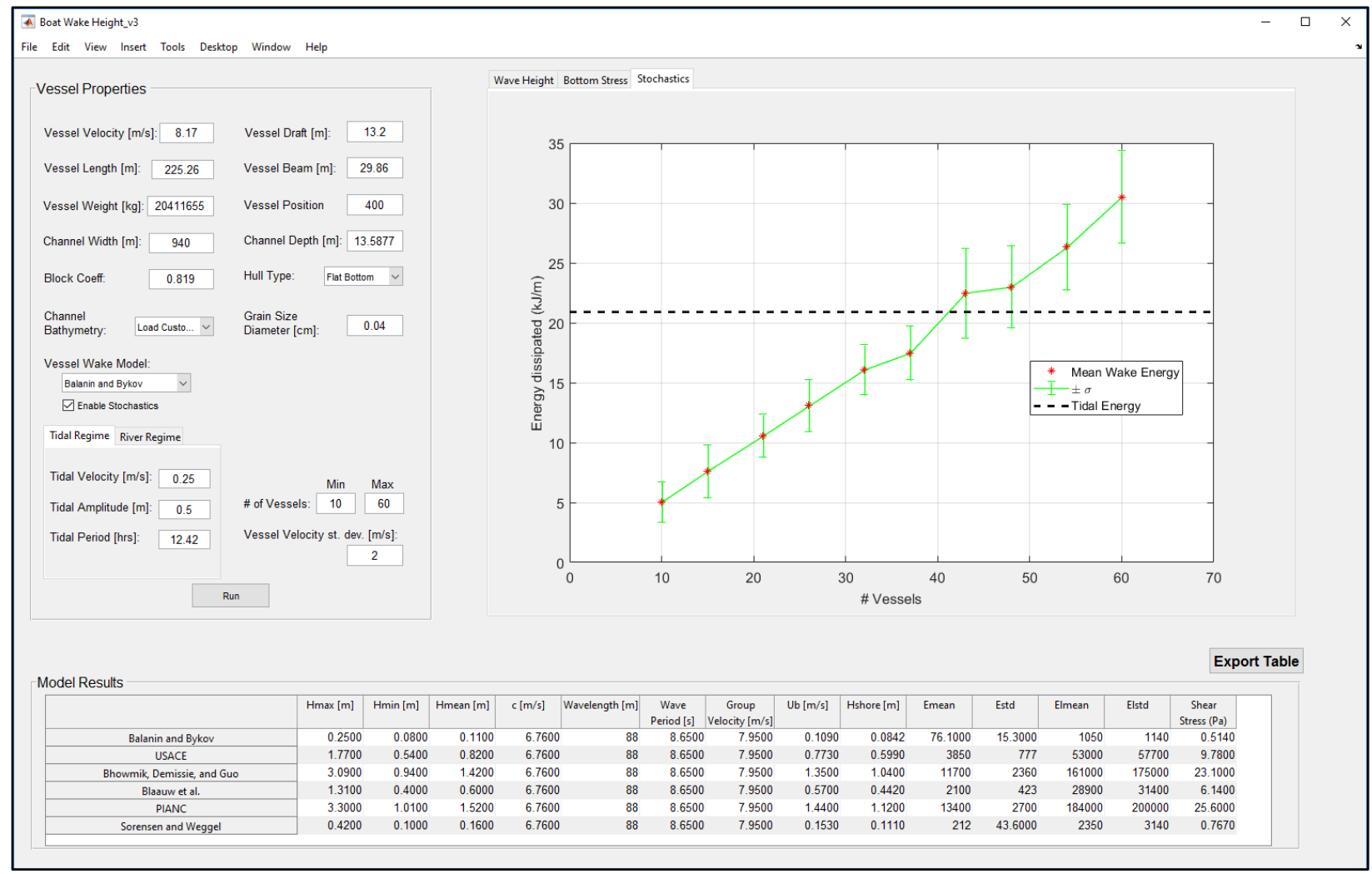

Figure 3. VWPT showing the Stochastics tab illustrating the mean wake energy (red markers) and standard deviation of mean wake energies (green error bars) from the stochastic calculations relative to the background tidal or river energy dissipation.

A check box within the Vessel Properties input panel controls the stochastic calculation. Checking the Enable Stochastics box activates several numeric input fields. The Tidal Regime tab is for vessels operating primarily in a tidally influenced region, where it is assumed that the majority of energy dissipation is due to tidal currents. The user will input the maximum tidal velocity over a tidal period, the amplitude of the tide, and the tidal period. In practice, the user should have knowledge of the tide characteristics for the area of interest. If the tidal information is insufficient or uncertain, then changing the values and re-running the model multiple times will help aid the user in understanding how this uncertainty scales in terms of the vessel wake energy. The River Regime tab is for vessels operating primarily in rivers where it is assumed that the majority of energy dissipation is due to river flow. The user will input the discharge, bed slope, and river width. The minimum and maximum number of vessel boxes allow the user to explore the effects of changing the number of vessels operating in the channel over a given timeframe.

In applications, complete knowledge of the vessel operating conditions such as distance between vessel and bank and vessel speed may be lacking. Operating conditions can vary between individual vessel passages. A more realistic representation should include a way to account for this variability. Furthermore, the user may be interested in exploring the vessel operational and environmental parameter space based on the level of uncertainty in project constraints, such as increases in vessel traffic due to higher commodities transport projections. The Standard Deviation (STD) box sets the STD of the vessel speed. Varying the STD is a direct way to explore the consequences of uncertainty in vessel speed for future operational forecasts. If the 
user is confident that vessel speed and position are fairly uniform, then a smaller STD is suggested. However, if the parameter space is not well constrained, a larger STD may be appropriate to incorporate greater uncertainty and explore the consequences of this uncertainty in situations where there is less information.

Model Results. The Model Results table lists the numerical values of selected vessel and wake parameters. The first three columns are the maximum $\left(H_{\max }\right)$, minimum $\left(H_{\text {min }}\right)$, and mean $\left(H_{\text {mean }}\right)$ wake height for the given wake algorithm. The parameter $c$ is the phase speed of the vessel wake packet (e.g., Sorensen 1997). The group velocity is computed from vessel velocity as described by Sorensen and Weggel (1984); then the period is calculated as the deep water value from the group velocity. The bottom orbital velocity $\left(U_{b}\right)$ is derived from linear wave theory, and the wave height at the shoreline $\left(H_{\text {shore }}\right)$ is the larger of the wave heights calculated at the shoreward limits of the vessel wake height calculation. The mean energy $\left(E_{\text {mean }}\right)$ and STD $\left(E_{s t d}\right)$ are the wave energy per unit planform area. The parameters, Elmean and Elstd are the mean and STD of the wave energy per unit length of shoreline, respectively. The last column is the shear stress measured at the shoreline. The Export Table button provides the option to save the input parameters and model output in an Excel spreadsheet, including the wake height and bottom stress as a function of distance from the sailing line.

SUMMARY: The VWPT is a desktop application to predict the relative energy dissipation and bottom shear stress due to vessel wake that may contribute to shoreline erosion. The rapid computational feature makes it possible to consider a wide variety of what-if scenarios for situations in which resources are limited, but a straightforward answer is required. The wake height models were developed with limited data and have not been widely validated. As such, there are several important caveats and limitations to consider when using the VWPT in practice. To provide a measure of the uncertainty due to the lack of extensive validation, the VWPT produces simultaneous output from several vessel wake models, which presumably reflects some of the variability in wake height for a given vessel type. The user can examine the variability in the output and use this as a rudimentary measure of the uncertainty in the model prediction. Even so, it is advised to obtain independent measurements to help place the results in terms of real-world conditions and to gain some measure of the variability on which to gauge the prediction. In this way, it is possible to identify the vessel wake algorithm that most closely matches the data for a given application or to determine if the uncertainty is larger than the user can justify and that more robust methods (e.g., numerical modeling, direct measurements) are better suited for the given application. Otherwise, there is no way to independently assess the wake model accuracy. When used as a relative estimation between different navigation scenarios, the VWPT can help elucidate the impact of changing vessel operating conditions. For example, it is possible to determine the required change in vessel speed needed to achieve a desired maximum energy threshold. In this case, it is not the absolute wake height or energy that is of interest but the relative change in wake energy due to altering vessel operations such as slower speeds or operating farther away from the shoreline. The user is advised to utilize data to help gauge the relative uncertainty in the VWPT.

The VWPT does not predict erosion but rather computes the shear stress and energy contained in the vessel wake. The VWPT is a proxy for wave-induced erosion potential as compared to the ambient tidal or river energy in the system. Real shoreline erosion should be measured or modeled using a higher-order computational tool such as a two- or three-dimensional morphodynamic modeling system if actual erosion predictions are required. 
The wake equations can easily be modified or replaced with higher-fidelity algorithms as additional validation data become available. Newer or modified formulas may also require input parameters that are not used in the existing models. The Graphical User Interface is dynamic, and can be easily modified to accommodate new or modified algorithms and input fields. Future development includes modifying the VWPT into a web-based application and further validation and refinement of the wake height equations using higher-order Boussinesq wave modeling and field data.

ADDITIONAL INFORMATION: This CHETN was prepared as part of the USACE CIRP and the Dredging Innovations Guidance (DIG) Program by Michael A. Hartman and Richard Styles, US Army Engineer Research and Development Center, Coastal and Hydraulics Laboratory, Vicksburg, MS. Questions pertaining to this CHETN may be directed to Richard Styles (richard.styles@usace.army.mil); the USACE CIRP Program Manager is Dr. Tanya M. Beck (Tanya.M.Beck@usace.army.mil); and the DIG Program Manager is Dr. Kenneth N. Mitchell (Kenneth.N.Mitchell@usace.army.mil). Additional information regarding CIRP may be obtained from the CIRP website http://cirp.usace.army.mill.

This ERDC/CHL CHETN-IV-121 should be cited as follows:

Hartman, M., and R. Styles. 2018. Vessel Wake Prediction Tool. ERDC/CHL CHETN-IV-121. Vicksburg, MS: US Army Engineer Research and Development Center. http://dx.doi.org/10.21079/11681/35153

\section{REFERENCES}

Balanin, V. V., and L. S. Bykov. 1965. "Selection of Leading Dimensions of Navigation Canal Sections and Modern Methods of Bank Protection." Sections 1-4, 21st Congress Proceedings, Permanent International Association of Navigation Congresses, Stockholm.

Bhowmik, N. G. 1975. "Boat-Generated Waves in Lakes." Journal of the Hydraulics Division, ASCE 101(11): 1465-1468.

Bhowmik, N. G., M. Demissie, and C.-Y. Guo. 1982. Waves Generated by River Traffic and Wind on the Illinois and Mississippi Rivers. Report UILIWRC- 82-167. Champaign, IL: University of Illinois, at Urbana-Champaign, Water Resources.

Bhowmik, N. G., T. W. Soong, W. F. Reichelt, and N. M. L. Seddik. 1991. Waves Generated by Recreational Traffic on the Upper Mississippi River System. Research Report 117. Champaign, IL: Department of Energy and Natural Resources, Illinois State Water Survey.

Blaauw, H. G., M. T. de Groot, F. C. M. Knaap, and K. W. Pilarczyk. 1984. "Design of Bank Protection of Inland Navigation Fairways." Proceedings of the Conference on Flexible Armoured Revetments Incorporating Geotextiles, London, 29-30 March 1984. London: Thomas Telford.

Dean, R. G. 1991. "Equilibrium Beach Profiles: Characteristics and Applications.” Journal of Coastal Research 7(1): 53-84.

Dean, R. G., and R. A. Dalrymple. 1991. "Water Wave Mechanics for Engineers and Scientists." Advanced Series on Ocean Engineering - Vol 2. Hackensack, NJ: World Scientific Publishing Co.

Maynord, S. T. 2005. "Wave Height from Semi-Planing and Planing Small Boats." River Research and Applications 21(1):1-17. 
Maynord, S. T. 2008. Boat-Wave-Induced Bank Erosion on the Kenai River, Alaska. ERDC/CHL TR-085. Vicksburg, MS: US Army Engineer Research and Development Center and Kenaitze Indian Tribe.

PIANC (Permanent International Association of Navigation Congresses). 1987. Guidelines for the Design and Construction of Flexible Revetments Incorporating Geotextiles for Inland Waterways. Working Group 4 of the Permanent Technical Committee. Brussels.

Shields, A. 1936. Application of Similarity Mechanics and Turbulence Research to the Sediment Movement. PhD thesis. Technical University Berlin. https://authors.library.caltech.edu/25992/1/Sheilds.pdf

Sorensen, R. M. 1997. Prediction of Vessel-Generated Waves with Reference to Vessels Common to the Upper Mississippi River System. Interim Report for the Upper Mississippi River - Illinois Waterway System Navigation Study. ENV Report 4. US Army Waterways Experiment Station, Vicksburg, MS; Department of Civil and Environmental Engineering, Lehigh University, Bethlehem, PA 18015.

Sorensen, R. M., and J. R. Weggel. 1984. "Development of Ship Wave Design Information.” Proceedings of the 19th Conference on Coastal Engineering, Houston, TX, 3-7 September 1984. Edited by B. L. Edge. American Society of Civil Engineers, New York, III, 3227-43.

Styles, R., and M. A. Hartman. 2018. Predicting Wave Height and Sediment Resuspension by Recreational Vessels in Coastal Plain Saltmarshes. ERDC/CHL TR-18-5. Vicksburg, MS: US Army Engineer Research and Development Center.

USACE LRH (US Army Corps of Engineers, Huntington District). 1980. Gallipolis Locks and Dam Replacement, Ohio River, Phase I - Advanced Engineering and Design Study. General Design Memorandum. Huntington, WV: US Army Engineer District, Huntington Corps of Engineers.

NOTE: The contents of this technical note are not to be used for advertising, publication, or promotional purposes. Citation of trade names does not constitute an official endorsement or approval of the use of such products. 